\title{
The effect of self-care nursing intervention model on self-esteem and quality of life among burn patients
}

\author{
Seham Mohamed Abd Elalem*1, Omima Said M.H. Shehata ${ }^{1}$, Safaa Ibrahem Shattla ${ }^{2}$ \\ ${ }^{1}$ Medical Surgical Nursing Department, Faculty of Nursing, Menoufia University, Egypt \\ ${ }^{2}$ Psychiatric and Mental Health Nursing Department, Faculty of Nursing, Menoufia University, Egypt
}

Received: November 3, 2017

Accepted: January 1, 2018

Online Published: January 13, 2018

DOI: $10.5430 /$ cns.v6n2p79

URL: https://doi.org/10.5430/cns.v6n2p79

\begin{abstract}
Objective: Burn injuries and their complications are considered the major health problems throughout the world as it has a negative effect on function of the burned part that result in psychological disturbance as depression, anxiety, irritability, body image dissatisfaction and post-traumatic stress disorder are common in burn patients that associated with adverse out comes including poor quality of life (QOL), low self-esteem, stigmatization and increase mortality. This study aimed to investigate the effect of self-care nursing intervention model on self-esteem and quality of life among burn patients.

Methods: A quasi-experimental research design was utilized. The study was conducted at burn unit of emergency hospital, Menoufia University at Menoufia governorate, Egypt. A convenience sample of 34 adult patients (one group pre/post test) with $2^{\text {nd }}$ degree burn and exposed to self care nursing intervention model that include (self-care requisites, stress management techniques and strategies for improving self esteem) in addition to routine hospital care. Three tools were used to fulfill: Tool I: Burn assessment tool, Tool II: Rosenberg Self-Esteem Scale and Tool III: World Health Organization Quality of Life (WHOQOL) scale.

Results: The main findings of the study there was statistically significant improvement of self-care knowledge related to burn management after implementing self-care model. There was statistically significant improvement of self-esteem and QOL among burn patients post-intervention than pre-intervention.

Conclusions: The overall findings in the present study revealed that implementing self-care nursing intervention model at burn unit was effective when providing care as it encouraged patient to be an active participant in care and had a significant improvement of self-care management, self-esteem and QOL among burn patients.

Recommendations: The self-care theory has shown to be the basis when providing nursing care as it helps in promoting therapeutic communication and trust relationship between the patient and the nurse so that encourage nurses to work and providing care with nursing theories.
\end{abstract}

Key Words: Self-care nursing intervention model, Self-esteem, Quality of life, Burn

\section{INTRODUCTION}

Burn injury is the major cause of mortality and disability worldwide as it considered a traumatic experience, it has a negative impact on the physical, emotional, and social aspects of quality of life (QOL); and affects the mental process of the patient. ${ }^{[1]}$ Burns are considered a public health problem, responsible for approximately 300,000 deaths each year worldwide. ${ }^{[2]}$ Every year, approximately 2.4 million

\footnotetext{
* Correspondence: Seham Mohamed Abd Elalem; Email: drsamahmasry@ gmail.com; Address: Medical Surgical Nursing Department, Faculty of Nursing, Menoufia University, Egypt.
} 
cases of burn injury occur in the world, 650,000 of which require treatment, 75,000 are hospitalized, and 8,000-12,000 die annually due to burn injuries. ${ }^{[3]}$ In the United States, burn injuries are one of the main causes of death, accounting for 3,240 deaths per year and 40,000 hospitalized patients annually. ${ }^{[4]}$

There are many health problems caused by burns such as physical problems that result from deformities or scar contractures, changes in skin color and body contour, and loss of body parts may limit the patient's return to previous activities, also visible burn scars may interfere with an individual's social activities and result in social isolation. ${ }^{[5]}$ Patients with extensive burn injuries suffer from an upsetting experience that effects on their normal thinking, behavior and lifestyle. The burn victim is stigmatized to an extent that they lose the capacity to appreciate the QOL and self-appraisal. The degree of damage done by burn injuries mainly affects the psychological well-being of the person especially if it involves the facial region. ${ }^{[6,7]}$

The study conducted by Van Loey et al. ${ }^{[8]}$ and Sidel et al. ${ }^{[9]}$ revealed that over $40 \%$ of burn patients required psychiatric treatment two years after the trauma and several patients (13\%-45\%) exhibited a post-traumatic stress disorder which begin at the time of the accident, remain during hospitalization, and may persist for years after hospital discharge. The rehabilitation process includes difficulties in performing physical activities due to scar contractures and pain, which are inherent to the treatment of scars after hospital discharge and obstacles in returning to social activities. ${ }^{[10]}$

Nurses have a key role in helping burn patients to adapt and cope with their new body image and provide the patients with information about treatment and complications of burn. Partridge in his study ${ }^{[11]}$ suggested that in the case of training and participation in self-care training programs was beneficial for burn patient as health care would be more expensive and cause impairment in the QOL. Promotion of selfcare helps the patients to have more control over their daily lives and be more able to deal with the social performance, thereby improving their QOL. Exercise training and empowering the patients through self-care strategies improves the self-management and reduces the pain and other injuries. ${ }^{[12]}$ However, in self-care education, the patient will educate and acquire enough knowledge and skills that help for decisions making and solving the self-related problems. ${ }^{[13]}$

The self-care nursing intervention model is one of the nursing theory which has been recommended by one of the nursing scholars named Dorothea Orem. This model focuses more on the aspects of self-care that includes, identify of human activities and carry out for their own sake in order to maintain their life and health and have constant feelings of well-being. ${ }^{[14]}$ Orem's Self Care Model is a suitable clinical guideline for planning and implementing the principles of self-care and is used as a conceptual framework to guide self-care programs. ${ }^{[15]}$

\subsection{Theoretical framework}

Nursing theory is constantly evolving and gaps between theory and practice can be filled over time. Orem giving the direction for assumptions through three factors, the first one is basic conditioning factors that influence the self-care agency and therapeutic self-care demand of the person; the second one is self-care agency enables the person to perform selfcare; the third one is self-care is directed toward accomplishing the self-care demand. A self-care deficit exists when the self-care demand of a person exceeds his self-care agency; and nursing agency enables the nurse to assess potential or actual self-care deficits of a person and construct a nursing system to address these deficits. ${ }^{[16]}$

Orem believes that individuals can develop themselves, for self-care is something learned and not instinctive. Besides, as the author emphasizes, human functioning includes physical, psychological, interpersonal, and social aspects. Self-care implies that a partnership between the patient and the professional is established, in which problems are identified and determine the actions and the appropriate type of intervention. However, the patients participation in the care plans is very important for the development of the plan itself, mainly for reducing patients dependency and encouraging them to become independent. ${ }^{[17]}$

Orem described the requisites of self-care theory which can be universal, concern development, and refer to the health disorder. The universal requisites which have a direct effect on human structure, its functions and life phases that interrelated and comprise common terms to designate the everyday life activities. These include maintenance of adequate air, food, water supply, care actions regarding the evacuation patterns, balance between activity and rest, balance between loneliness and social interaction, avoiding harms to one's life and body functioning, and promoting human functioning and development. The items regarding the self-care requisites for development had the purpose to find what actions the individual performs to promote self-care. The self-care requisites regarding health disorders explored the conditions related to the therapy, knowledge about burn care, control of complications, and access to health services. ${ }^{[18]}$

For implementing patient care, Orem suggests three steps. In the beginning, the first contact with the patient, the nurse interview and communicate health care needs to the individual. 
This initial contact should be established, legitimized, and adequate according to the evidence required by nursing. Patient interaction is the source to identify the requisites, systems and new self-care demands, as well as diagnosis and nursing prescriptions. In the second step, the nurse creates a system that determine the therapeutic demands and ways to care for the patient. The continuity of care is ensured by the help of family members or those responsible for providing care, who will act now and in the future. Then evaluate the patients potential for self-care. It is the moment to acknowledge, organize, and document the effective value of nursing. The third step is the preparation of the patient, family or person responsible for the self-care to become independent from the nurses actions. This person is considered as a guidance for the nursing prescription. In this moment, an agreement is established with the patient about his needs and the factors that could possibly interfere in this new adjustment. Next, the actions established according to the care demand are documented. ${ }^{[19]}$

\subsection{Significance of the study}

Burns represent not only a very serious illness with a potential fatal complications, but also profound a traumatic events with a significant potential for development of complex problems, in addition to burn patients need to accommodate with their new body image and the processes that lead to changes in their lives due to the injuries, also the recovery from burn need providing health care that involve management of physical, psychological and social problems and prevention of complications of burn that will be more expensive and cause impairment in the QOL.

From all the above, the health care providers when training and participating burn patients in the self-care training programs should be more effective and beneficial as it helps them to have more control over their daily lives and be more able to deal with the social performance, thereby improving their self-management, self-esteem and QOL, in addition to reduce stress, pain and other injuries. This indicates that there is a need for more researching in this area for improving self-esteem and QOL through application of self-care program, so the researchers intended to carry out a study in order to investigate the effect of self-care nursing intervention model on enhancement of the self-esteem and QOL.

\subsection{Aim of the study}

This study aimed to investigate the effect of self-care nursing intervention model on self-esteem and QOL among burn patients.

Published by Sciedu Press

\subsection{Research hypothesis}

- The study group will have increasing self-care knowledge related to burn management at post intervention than pre intervention.

- The study group will have improvement of self-esteem and QOL mean score at post intervention than pre intervention.

\section{Methodology}

\subsection{Research design}

Quasi-experimental research design (one group pre/post test) was utilized to achieve the aim of the study.

\subsection{Research setting}

This study was conducted at Burn Unit of Emergency Hospital, Menoufia University at Menoufia governorate, Egypt.

\subsection{Subjects}

\subsubsection{Sample size}

Based on the past review of literature that examine the same outcome and found significant differences, a sample size has been calculated using the following equation: $n=\left(z^{2} \times p\right.$ $\times q) / D^{2}$ at power $80 \%$ and CI $95 \%$, the sample size was conducted to be 34 burn patients.

\subsubsection{Study sample}

A convenience sample technique of 34 adult patients who were admitted to a burn unit of emergency hospital, Menoufia University were selected according to the following inclusion criteria:

\subsubsection{Inclusion criteria}

- Adult patients of both sexes in age group 21-60.

- Conscious, able to cooperate and communicate to participate in the study.

- The patient has $2^{\text {nd }}$ degree burn: wound total surface area of burn is less than $25 \%$ or mixed partial and full thickness burn with less than $10 \%$ full thickness injury. ${ }^{[20]}$

\subsubsection{Exclusion criteria}

- Patients who had superficial and third degree burn.

- History of psychiatric disorders.

\subsection{Tools of the study}

Based on the review of the related literature, three tools were utilized by the researchers as the following. 


\subsubsection{Tool (1): Burn assessment tool}

It was developed by the researchers after reviewing the related literature. This tool was designed and used for assessment of burn patient and it composed of three parts as the following:

Part (1): Sociodemographic data: including patient's age, sex, level of education, occupation, marital status, income.

Part (2): Assessment of burn: It was composed of items related to date of admission and discharge from the unit, site, cause, extent, degree and depth of burn, place of accident, causative agent.

Part (3): Questions to assess patient's knowledge related to burn as definition, causes, types of burn, first aid of burn, complications of burn, and self-care requisites that include "adequate nutrition, proper position and range of motion exercise, and relaxation techniques for reducing stress and anxiety". It was composed of 10 questions.

Scoring system: Part three consisted of ten questions; each question rating from $0-2$. Zero indicates incorrect answer or never adhere to self care requisites, 1 indicates incomplete correct answer or sometimes adhere to self care requisites and 2 indicates completely correct answer or always adhere to self care requisites. All scores were summed and the total scores were from (0-20). The scoring system was categorized as follow according to Al-Khaled et al. ${ }^{[21]}$

- Good knowledge from $80 \%$ to $100 \%$ (from 16 to 20).

- Fair knowledge from $60 \%$ to less than $80 \%$ (from 12 to less than 16).

- Poor knowledge less than $60 \%$ (less than 12 ).

\subsubsection{Tool (2): Rosenberg's global self-esteem scale}

Arabic version of Rosenberg's global self-esteem scale was translated by Garas, Ahmed and Bader ${ }^{[22]}$ also applied by Hassan. ${ }^{[23]}$ This scale was designed to measure the global negative and positive self-attitudes. It consists of 10 statements ( 5 statements are phrased positively and 5 statements are phrased negatively). These statements are rated on a 4-point scale, which are: (4) strongly agree, (3) Agree, (2) Disagree, (1) Strongly disagree. According to these answers, scoring ranges from 1 to 40, with 40 indicating the highest possible score. Scoring for negative answers was reversed, i.e., 1 for strongly agree and 4 for strongly disagree, and so on. Total scores were graded as follows:

- Low: below 20.

- Moderate: from 20 to less than 25.

- High: from 25 to more than.
2.4.3 Tool (3): World Health Organization Quality of Life (WHOQOL, 1997) scale s24] $^{[2]}$

WHOQOL-BREF questionnaire contains a set of 26 questions, and answers given to these questions will generate scores for four domains: physical, psychological, social relationships and the environmental factors. In addition, there are two questions that are analyzed separately: a question related to the individual perception of QOL in general and scored from 1 to 5 as 1 means very poor, 2 means poor, 3 (neither poor nor good), 4 (good), 5 (very good), and question 2 , which refers to the individual's perception of his health in general and scored from 1 to 5 as 1 means very dissatisfied, 2 means dissatisfied, 3 means neither satisfied nor dissatisfied, 4 means satisfied, 5 means very satisfied.

Physical health: Consists of seven items that were dependence of treatment, energy and fatigue, mobility, presence of pain and discomfort, sleep and rest, activities of daily living, and perceived working capacity. Each item takes the score from 1 to 5 . The score 1 means an extreme amount, score 2 means very much, score 3 means a moderate amount, score 4 means a little, score 5 means not at all.

Psychological well-being: Consists of six items that include affect, positive self- concept, negative feelings, higher cognitive functions, body image, and spirituality. Each item takes scores from 1 to 5 . The score 1 means not at all, score 2 means little, score 3 means moderately, score 4 means mostly, score 5 means completely.

Social relations: Consists of three items that include social contacts, family support, and sexual activity. Each item takes scores from 1 to 5 . The score 1 means very dissatisfied, score 2 means dissatisfied, score 3 means neither satisfied nor dissatisfied, score 4 means satisfied, score 5 means very satisfied.

Environmental factors: Consists of eight items that include freedom, quality of home environment, physical safety, and security, involvement in recreational activity, quality of health and social care, and accessibility to services and takes the score from 1 to 5 . The score 1 means not at all, score 2 means a little, score 3 means moderately, score 4 means mostly and score 5 means completely. The participants were chosen the score according to their felling. The domain scores are scaled in a positive direction as higher scores denote higher QOL.

\subsection{Reliability}

The tools used in this study were tested for its reliability using test-retest reliability and proved to be strongly reliable at 0.90 for tool one and at 0.87 for tool two. Tool three reliable at 0.84 . 


\section{Validity of the tools}

The tools for data collection were tested for face and content validity by a panel of experts in medical and psychiatric health nursing specialties to ascertain relevance and completeness. Required modifications were carried out accordingly.

\subsection{Process of data collection}

\subsubsection{Preliminary phase}

Review of relevant literature was carried out to get a clear picture of all aspects of the research topic and variables to design the data collection instruments.

Administration and ethical consideration: official letter obtained from Faculty of nursing to the responsible authorities of Menoufia university hospital (the hospital administrator and the director of burn unit) and agreement to fulfill the study was acquired after clarification the purpose of the study.

A pilot study was done for $10 \%$ of the study subjects. This was conducted to determine visibility, pertinence and time acquired for completing the research instruments. The required adjustment were done according to pilot study. These patients were excluded from the sample.

Preservation of subject rights: patients were confirmed that participation in the study was voluntary and the confidentiality were achieved, also they informed that refusal to participate wouldn't effect on the care provided and they have the freedom to withdraw from the study at any time.

\subsubsection{Application phase}

(1) The data was collected over seven months from October 2016 to April 2017, all patients who agreed to participate in the study and fulfilled the inclusion criteria were involved in the research. The total number of them was 34 patients, divided into 2 groups ( group for males consisted of 16 patients and group for females consisted of 18 patients). Then the subjects were divided into 7 groups ranging from 4 to 5 patients in each group to attend 8 sessions, two sessions per week, every session taking one hour within two days/week (Saturday and Monday from 10 a.m. to 11.30 p.m.) because these days are suitable for patients and researchers and this time after taken medication and dressing (note, the same one group for two days for one month) then made post test for that group and worked with other group. Each group take the intervention separately and the other group start the intervention after one finished. The period of implementation was 4 weeks for each group. The implementation of the program sessions was achieved within 7 months for all groups. Most of patients follow through the telephone after discharge and the others follow through home visit to assure the continuity of care and application of the program.
(2) The nursing intervention was developed and given during 8 sessions. The general and specific objectives were achieved through several teaching methods such as brainstorming, lecture, discussion, and handouts, and the use of illustrated media (video, pictures and computer programs). At the end of each session summary, feedback and further clarifications were done for vague items and time was allotted for asking any questions and explaining homework assignments for the next session.

The intended learning outcome objectives (ILOS) for the nursing intervention program sessions were: define burn, identify causes and types of burn, enumerate first aid of burn, list complications of burn, enumerate self-care strategies of burn patients based on Orem's theory, define concept of self-esteem, causes of low self-esteem and train the patients how can improve their self-esteem, also QOL will improved through applying stress management techniques as, deep breathing exercise and progressive relaxation (active and passive progressive relaxation), visualization for relaxation and meditation.

The sessions for intervention were:

Session 1: In this session the researchers introduced themselves to the patients and getting the patients to know each other. It was concerned with open discussion to identify, integrate the group, clarify the aim of the time table allowed for interventions. The researchers interviewed with the patients at the burn unit where collecting the initial data by using the pre-test instruments 1 (part 1,2 and 3), 2 and 3. At the end of this session, the researchers determine the other meeting times with the patients. Also in this session the researchers determine patient's problems, then designed the possible care plan for solving these problems. This session took about 90 minutes.

Sessions 2 and 3: The researchers discussed with the patient the intervention priorities and adapted a care plan which approved and was adequate to meet patient's perceived needs. The goals were compatible with the diagnosis and had the objective to capacitate the patient to become a self-care agent and achieve the intended learning outcome objectives that concerned with ascertaining knowledge about definition, causes, and types of burn, first aid and complications of burn. Enumerate self-care strategies of burn patients based on Orem's theory to achieve the universal self-care requisites as breathing without difficulties, adequate fluid and food intake, void and bowel elimination without difficulty, proper activity and rest, social interaction through learning of methods of communication and prevention of hazards. This session also concerned with the demonstration of breathing and coughing exercises, proper position and range of motion 
(active and passive) for the affected part. Each session (2 and 3) took about 45-60 minutes.

Sessions 3: In this session encourage patient to practice the stress management techniques as, deep breathing exercise and Progressive Relaxation (active and passive progressive relaxation), Visualization for relaxation and Meditation through the following steps: Train the patients for body scanning technique through encouraged them to take a comfortable position while making sure that your supine is straight, begin by closing eyes and turning their attention to their internal world, focus on their toes and move up slowly. Ask themselves "where am I tense?" Become aware of muscles in your body especially the parts of your body you feel tense or tight, it took 60 minutes.

Session 4 and 5: This session helped the patients to describe the personal experience related to psychological response to burn and teach them the steps of deep breathing and demonstrate it. Teach the patients how to take deep, healthful breath through inhale deeply while saying the number 10 then, exhale slowly, letting out all the air in your lungs inhale a gain, saying the number 9 and so on. The researcher explained the steps of progressive muscle relaxation technique (active and passive progressive relaxation). Before doing the exercise of progressive muscle relaxation, one must recognize that there are four muscle groups are covered in this order: 1 - hands, forearms, and biceps; 2 - head, face, throat, and shoulders; 3 chest, abdomen, and lower back; 4 - thighs, buttocks, calves, and feet. In active progressive relaxation, each muscle or muscle grouping is tensed for 5 to 7 seconds and then relaxed for 10 to 15 seconds, then repeating the cycle. The final step is meditation and visualization techniques that focus on asking the patient to use of imagination and positive thinking in an effort to reduce the body's response to stress through creating appositive mental picture, it took 60-90 minutes.

Sessions 6 and 7: This sessions were focused on the definition of self-esteem, causes of low self-esteem and steps of improving self-esteem. Training the patients how can improve their self-esteem through different situations given to the patient and learn him how can be assertive not passive or aggressive and help him to accept the new body image and adapt with it. Watching for videos about self-esteem improvement and application, re-demonstration for practices and skills in the videos, also application of self-esteem improvement process for dealing with main problems that faced patients in daily living situation with healthy way, each session took about 60-90 minutes.

Session 8: the researchers summarizing the main points of the program. The post-test questionnaires were provided immediate finishing the all sessions to evaluate the effective- ness of the intervention program (after 8 weeks) for every group.

To enhance maintenance of program gains, the researchers recorded a personalized audio and writing file for each patient consisting of a summary of the therapy as well as the in session mindfulness exercises to evaluate the efficacy of the implemented interventions, comparing how the nursing diagnoses were presented and identifying the need for further care actions. This referred to the third step of the Orem theory which prepared the patient for the independence phase for performing the self-care activities. It took 25-35 seconds.

An illustrative colored booklet was prepared in a simple Arabic language with an illustrative pictures used to guide an illiterate patients to understand the data related to intervention.

Every patient of the study group was evaluated 2 times; the first time when the patient admitted to burn unit preintervention by using tool 1 part 1,2 and 3, tool 2 and tool 3 , the second time for post-test by using tool 1 part 3, tool 2 and tool 3 .

\subsubsection{Evaluation phase}

The researchers interviewed the patients for evaluation at post intervention after each group finished the intervention (one month) by using post-test assessment tools: (1) part 3 , 2 and 3.

\subsection{Data processing and analysis}

Data were collected, tabulated, statistically analyzed using an IBM personal computer with Statistical Package of Social Science (SPSS) version 20 where the following statistics were applied. Descriptive statistics: in which quantitative data were presented in the form of mean $(\bar{x})$, standard deviation $(S D)$, range, and qualitative data were presented in the form numbers and percentages. Analytical statistics: used to find out the possible association between variables. and comparison was done for study group between pre and post intervention to determine the effect of self-care nursing intervention model on self-esteem and QOL among burn patients. The used tests of significance included: Paired $t$-test: is a test of significance used for comparison between two related groups having quantitative variables. McNemar's test assess the significance of the difference between two correlated proportions. Chi-square test $\left(\chi^{2}\right)$ : was used to study association between two qualitative variables. Pearson correlation $(r)$ : is a test used to measure the association between two quantitative variables. $P$-value of $>.05$ was considered statistically non-significant, $p$-value of $<.05$ was considered statistically significant and $p$-value of $<.001$ was considered statistically highly significant. 


\section{Results}

Table 1 illustrates that the more than half of the patients were female $52.9 \%$ and came from a rural region (58.8\%) with a mean age of $40.4 \pm 11.8$ years. Half of the patients $(50 \%)$ were married and more than one third of the patients $(41.2 \%)$ had secondary education. More than half of the patients $(64.7 \%)$ did not have enough family income and half of the patients $(50 \%)$ weren't have work or housewife.

Table 1. Sociodemographic characteristics of studied group $(\mathrm{N}=34)$

\begin{tabular}{|c|c|c|}
\hline Sociodemographic data & No. & $\%$ \\
\hline \multicolumn{3}{|l|}{ Age/years } \\
\hline - $\operatorname{Mean} \pm S D$ & \multicolumn{2}{|l|}{$40.4 \pm 11.8$} \\
\hline - Range & \multicolumn{2}{|l|}{$24-59$} \\
\hline \multicolumn{3}{|l|}{ Gender } \\
\hline - Male & 16 & 47.1 \\
\hline - Female & 18 & 52.9 \\
\hline \multicolumn{3}{|l|}{ Residence } \\
\hline - Urban & 14 & 41.2 \\
\hline - Rural & 20 & 58.8 \\
\hline \multicolumn{3}{|l|}{ Marital state } \\
\hline - Single & 6 & 17.6 \\
\hline - Married & 17 & 50.0 \\
\hline - Widow & 5 & 14.7 \\
\hline - Divorced & 6 & 17.6 \\
\hline \multicolumn{3}{|l|}{ Educational level } \\
\hline - Illiterate & 6 & 17.6 \\
\hline - Read and write & 3 & 8.80 \\
\hline - Basic education & 9 & 26.5 \\
\hline - Secondary education & 14 & 41.2 \\
\hline - High education & 2 & 5.90 \\
\hline \multicolumn{3}{|l|}{ Occupation } \\
\hline - Manual work & 7 & 20.6 \\
\hline - Administrative work & 10 & 29.4 \\
\hline - Not work or house wife & 17 & 50.0 \\
\hline \multicolumn{3}{|l|}{ Income } \\
\hline - Enough & 12 & 35.3 \\
\hline - Not enough & 22 & 64.7 \\
\hline
\end{tabular}

Table 2 shows that more than two third of the patients $(73.5 \%)$ burned at house and mean of hospitalization day $18.5 \pm 4.47$ with the range 13-30 days. About half of patients (44.1\%) were burned by flam followed by $(41.2 \%)$ were burned by hot fluids. More than half of patients $(58.8 \%)$ were burned at other parts of the body without face. More than half of the patients $(61.8 \%)$ had extent of burn from $10 \%-20 \%$.

Figure 1 clarifies that only about $20.6 \%$ of the patients presented satisfactory knowledge related to burn and self-care management pre intervention while the poor knowledge among the studied patients pre intervention is $79.4 \%$ decreases to $8.8 \%$ post intervention and the good knowledge Published by Sciedu Press improved from zero to $73.5 \%$ post intervention.

Table 2. Burn data of studied group $(\mathrm{N}=34)$

\begin{tabular}{lll}
\hline Burn data & No. & $\%$ \\
\hline Hospitalization days & \multicolumn{2}{l}{ \% } \\
- Mean $\pm S D$ & $18.5 \pm 4.47$ \\
- Range & \multicolumn{2}{l}{} \\
Place of burn & 25 & 73.5 \\
- In house & 9 & 26.5 \\
- Out the house & & \\
Cause of burn & 15 & 44.1 \\
- Flam & 14 & 41.2 \\
- Hot fluids & 5 & 14.7 \\
- Chemicals & & \\
Site of burn & 14 & 41.2 \\
- Face with other parts of the body & 20 & 58.8 \\
- Other parts of the body without face & & \\
Extent of burn & 13 & 38.2 \\
- Less than 10\% & 21 & 61.8 \\
- From 10\%-25\% &
\end{tabular}

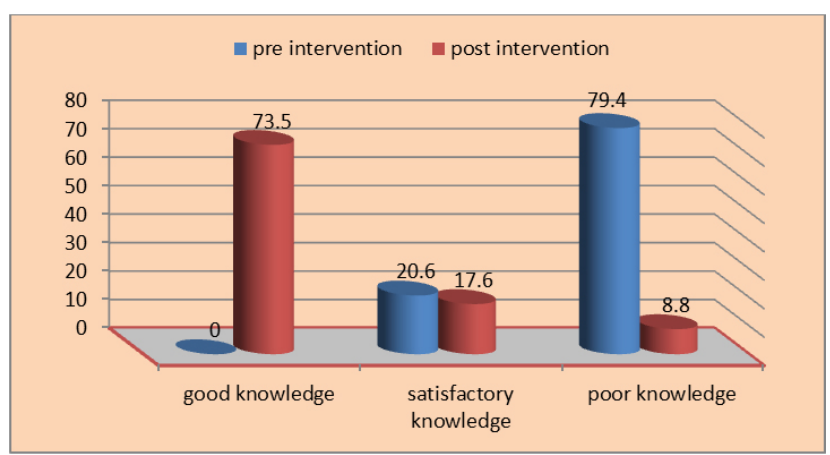

Figure 1. Self-care knowledge at pre and post intervention of studied group $(\mathrm{N}=34)$

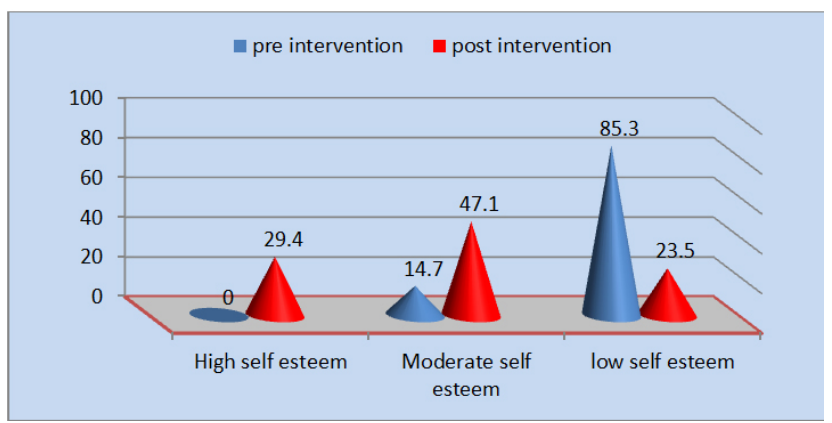

Figure 2. Self-esteem at pre and post intervention of studied group $(\mathrm{N}=34)$

Figure 2 indicates that about $(85.3 \%)$ of the patients expressed low self-esteem at pre intervention that became (47.1\%) of the patients had moderate self-esteem and (29.4\%) had high self-esteem at post intervention but only $(23.5 \%)$ still expressed low self-esteem at post intervention. 
Table 3. QOL domains and total score at pre and post intervention of studied group $(\mathrm{N}=34)$

\begin{tabular}{lllll}
\hline Studied variables & $\begin{array}{l}\text { Pre intervention } \\
(\text { Mean } \pm \boldsymbol{S D})\end{array}$ & $\begin{array}{l}\text { Post intervention } \\
(\text { Mean } \pm \boldsymbol{S D})\end{array}$ & Paired $\boldsymbol{t}$-test & $\boldsymbol{p}$-value \\
\hline Physical domain & $21.0 \pm 1.37$ & $27.1 \pm 0.80$ & 23.5 & $<.001$ \\
Psychological domain & $15.0 \pm 0.86$ & $23.2 \pm 0.86$ & 42.4 & $<.001$ \\
Social domain & $13.2 \pm 1.41$ & $8.55 \pm 1.07$ & 37.6 & $<.001$ \\
Environmental domain & $13.4 \pm 1.04$ & $31.5 \pm 3.26$ & 78.6 & $<.001$ \\
Total quality of life & $57.2 \pm 3.26$ & $104.1 \pm 2.88$ & 93.4 & $<.001$ \\
\hline
\end{tabular}

Note. Significance $p$-value $<.05$

Table 4. Adherence to self care requisites among studied group at pre and post-intervention $(\mathrm{N}=34)$

\begin{tabular}{|c|c|c|c|c|c|c|}
\hline \multirow{3}{*}{$\begin{array}{l}\text { Frequency for adherence } \\
\text { of self-care requisites }\end{array}$} & \multicolumn{4}{|c|}{ Studied group $(\mathbf{N}=34)$} & \multirow{3}{*}{$\chi^{2}$} & \multirow{3}{*}{$p$-value } \\
\hline & \multicolumn{2}{|c|}{ Pre-intervention } & \multicolumn{2}{|c|}{ Post-intervention } & & \\
\hline & No & $\%$ & No & $\%$ & & \\
\hline \multicolumn{7}{|c|}{ 1.Performing breathing and coughing exercise: } \\
\hline - Always & 0 & 0.00 & 25 & 73.5 & \multirow{3}{*}{48.85} & \multirow{3}{*}{$<.001$} \\
\hline - Sometimes & 5 & 14.7 & 7 & 20.6 & & \\
\hline - Never & 29 & 85.3 & 2 & 5.9 & & \\
\hline \multicolumn{7}{|l|}{ 2. Sufficient fluid intake: } \\
\hline - Always & 21 & 61.8 & 33 & 97.1 & \multirow{3}{*}{12.95} & \multirow{3}{*}{$<.001$} \\
\hline - Sometimes & 13 & 38.2 & 1 & 2.9 & & \\
\hline - Never & 0 & 0.00 & 0 & 0.00 & & \\
\hline \multicolumn{7}{|l|}{ 3. Adequate nutrition: } \\
\hline - Always & 3 & 8.8 & 24 & 70.6 & \multirow[t]{3}{*}{42.40} & \multirow{3}{*}{$<.001$} \\
\hline - Sometimes & 4 & 11.8 & 9 & 26.5 & & \\
\hline - Never & 27 & 79.4 & 1 & 2.9 & & \\
\hline \multicolumn{7}{|l|}{ 4. Performing activity (ROM): } \\
\hline - Always & 0 & 0.00 & 21 & 61.8 & \multirow{3}{*}{27.23} & \multirow{3}{*}{$<.001$} \\
\hline - Sometimes & 2 & 5.9 & 9 & 26.5 & & \\
\hline - Never & 32 & 94.1 & 4 & 11.7 & & \\
\hline \multicolumn{7}{|c|}{ 5. Bowel elimination without problems: } \\
\hline - Always & 18 & 52.9 & 28 & 82.4 & \multirow{3}{*}{6.77} & \multirow{3}{*}{.034} \\
\hline - Sometimes & 14 & 41.2 & 5 & 14.7 & & \\
\hline - Never & 2 & 5.9 & 1 & 2.9 & & \\
\hline \multicolumn{7}{|c|}{ 6. Urinary elimination without problems: } \\
\hline - Always & 12 & 35.3 & 23 & 67.6 & \multirow{3}{*}{7.18} & \multirow{3}{*}{.028} \\
\hline - Sometimes & 13 & 38.2 & 7 & 20.6 & & \\
\hline - Never & 9 & 26.5 & 4 & 11.7 & & \\
\hline \multicolumn{7}{|c|}{ 7. Performing progressive muscle relaxation techniques: } \\
\hline - Always & 0 & 0.00 & 27 & 79.4 & \multirow{3}{*}{68.00} & \multirow{3}{*}{$<.001$} \\
\hline - Sometimes & 0 & 0.00 & 6 & 17.7 & & \\
\hline - Never & 34 & 100.0 & 1 & 2.9 & & \\
\hline
\end{tabular}

Note. Significance $p$-value $<.05$

Table 3 shows improvement in the total QOL and all dimensions of the QOL instrument (physical health, psychological wellbeing, social relationships and environmental factors) at post intervention with a highly statistically significant difference $p<.001$.

Table 4 indicates that there is statistically significant adherence to self care requisites among studied group at postintervention for performing breathing and coughing exercise, sufficient fluid intake, adequate nutrition, performing activ- ity, bowel elimination without problem, urinary elimination without problem, Performing progressive muscle relaxation techniques as $p$-value of $<.05$.

Table 5 illustrates that there is statistically significant relation between self-esteem and site and extent of burn at post intervention as $p=.037$ and .006 .

Table 6 clarifies that there is statistically significant positive correlation between self-esteem and QOL at psychological and social domain post intervention as $p=.014$ and .029 . 
Table 5. Relation between burn data and self-esteem post intervention of studied group $(\mathrm{N}=34)$

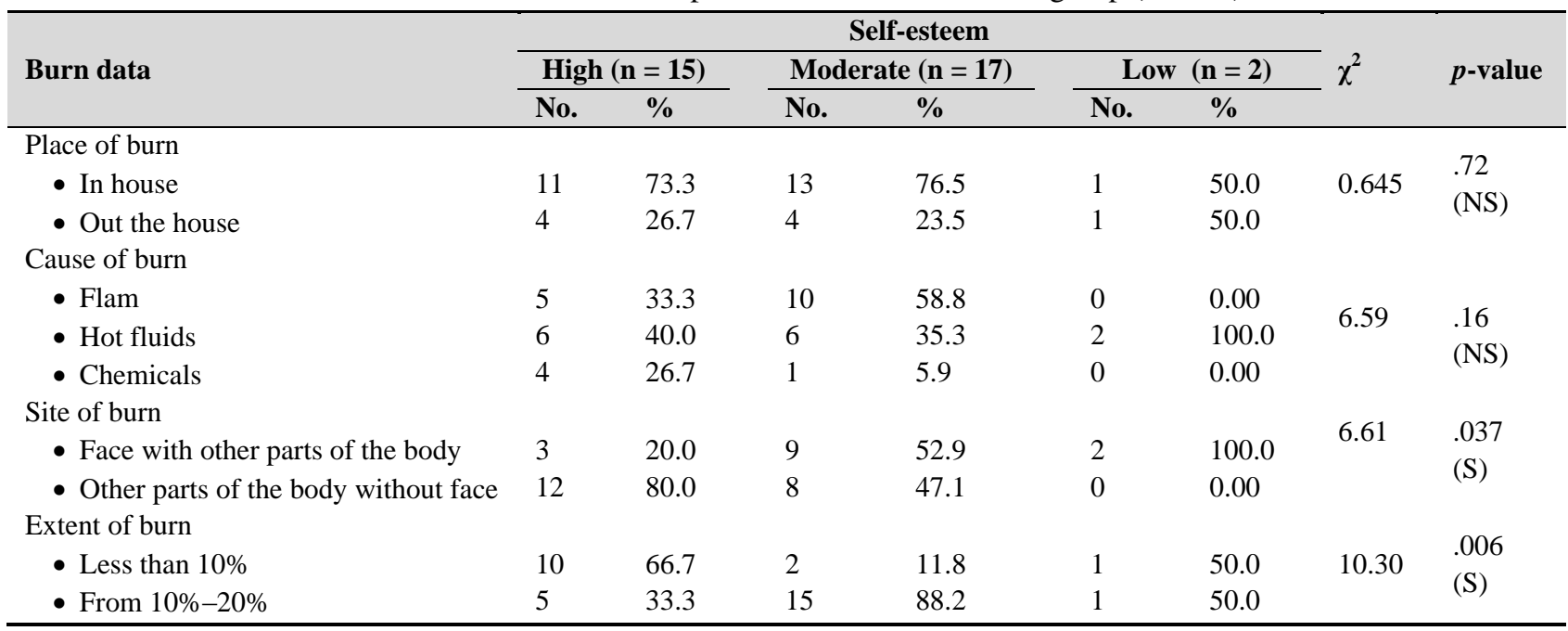

Note. Significance $p$-value <.05; NS: non-significant; S: significant

Table 6. Correlation between self-esteem and QOL post-intervention of studied group $(\mathrm{N}=34)$

\begin{tabular}{lll}
\hline \multirow{2}{*}{ Quality of life } & Self-esteem & \\
\cline { 2 - 3 } & $\mathbf{R}$ & $\boldsymbol{p}$-value \\
\hline Physical domain & 0.316 & $.069(\mathrm{NS})$ \\
Psychological domain & 0.417 & $.014(\mathrm{~S})$ \\
Social domain & 0.375 & $.029(\mathrm{~S})$ \\
Environmental domain & 0.281 & $.108(\mathrm{NS})$ \\
\hline
\end{tabular}

Note. Significance $p$-value <.05; NS: non-significant; S: significant

\section{Discussion}

The therapeutic demand of self-care described by Orem provides a description of basic conditioning factors that influence patient and environment (aspects of the patients life, health or wellness), recognizing the effective instruments and specific techniques, chosen by the patient, which can be used to change development factors; self-care agency enables the person to perform self-care. So that self-care is directed toward accomplishing the self-care demand and the patients interacted with supporting social networks and the care provider could solve any problems hinder the self-care actions. $^{[25]}$

\subsection{Regarding sociodemographic characteristic and burn data of studied group}

The result of the current study showed that the mean age of the studied patients was $40.4 \pm 11.8$ years and more than half of patients were female $(52.9 \%)$. This result in congruent with Faisal et al., ${ }^{[26]}$ who found the majority of the participants were females. This may be due to the female more contact with fire at home. The study revealed that more than half of the study patients coming from rural areas and house wife. This result on the contrary with Tirumala et al., ${ }^{[27]}$ who mentioned that more than three quarter of the patients from rural back ground and most of them were house wives. While Faisal et al. ${ }^{[2]}$ reported that $38 \%$ individuals were dsqqunemployed, $37 \%$ were employed, $21 \%$ were house wives. Also our study reported that the most common place of burn at home rather than outside the home. This result is in contrast with Faisal et al., ${ }^{[25]}$ who revealed that the majority of the cases were accidental industrial burns (79\%) which took place at work while the lowest percent at house $(33 \%)$. This may be due to the study subject had secondary education with low income and didn't follow the safety measures when dealing with fire at home that leading to accidental burn. Regarding to income, the study revealed that more than two third of burn patients not have enough income. This result congruent Ciofi-Silva et al., ${ }^{[28]}$ who mentioned that burn injuries are associated with low income, poverty, unemployment, poor, housing and living conditions. This may be due to the majority of the subjects were female, had secondary education and housewife didn't have work that effect on the family income.

Regarding the causes of the burn, the study showed that a flam was the major cause of the burn. This result matched with Hashemi et al., ${ }^{[29]}$ who found that the main cause of burn was thermal (78.6\%), also Zorita et al. ${ }^{[30]}$ found the main cause of burn injuries was a flam. Concerning site and extent of the burn the study revealed the most site of burn the studied patients exposed to it was in other parts of the body without face and extent of the burn from 10\%-25\%. This result consisted with Hashemi et al., ${ }^{[29]}$ who reported the main site of burn was in the hand with highest percent while arms and pelvis were the lowest percent, and Zorita et al. ${ }^{[30]}$ found the mean burn size was $21 \% \pm 17.10 \%$ of 
total body surface area (range from 1\%-60\%). This may be due to that the majority of the study subjects were female, housewife and had the accidental burn at home.

\subsection{Regarding self-care program and level of knowledge about burn of studied group}

Regarding to effect of the self-care program on level of knowledge, the result of our study showed that the patient's knowledge about burn, physical and psychological complications of burn and its managements were improved post intervention rather than pre intervention with highly statistical significance. This result consistent with Jang et al. ${ }^{[31]}$ and Hashemi et al., ${ }^{[29]}$ who reported that the level of knowledge about burn and self-care improved two-months after the interventions. furthermore in a study conducted by Radwan et al., ${ }^{[32]}$ who found that implementing a 7 day rehabilitation program for 2 weeks would improve physical, social and mental function of the patients in the experimental group. This may be due to teaching patients throughout the different sessions and also related to shared situations and this may be due to the researcher expectation that the regular attendance of the patients and showing their interest within sessions activities this is a good indicator that the intervention was positively impact their competence, performance and applicability for the subjects.

\subsection{Considering self-care program and its influence on self-esteem of studied group}

The results revealed that the burn patients have poor selfesteem pre intervention but it improved post intervention than pre intervention with highly statistical significant. This result congruent with Faisal et al., ${ }^{[32]}$ who reported that the complications of burn, especially visible scars, may result in emotional and social distress, which may lead to reduced self-esteem, sadness, and social isolation. Also the study reported that the overall score of Self-esteem Scale of burn victims with facial injury was found to be low with $66 \%$ of subjects presenting below average scores. In the same line Poorgholami et al., ${ }^{[32]}$ who reported that there was a significant difference between the mean self-esteem score in both groups before and after intervention and increase the means score in the intervention group.

\subsection{Regarding self-care program and its influence on QOL of studied group}

The results showed that the mean QOL score was significantly lower in cases pre intervention but in post intervention overall mean score increased. This result congruent with Pishnamazy et al., ${ }^{[34]}$ who founded that burn patients are faced with many problems which affected their QOL, especially the psychological aspects. Elsherbiny et al. ${ }^{[35]}$ revealed that burns has several complications on most dimensions of the QOL of patients with burns. In the same line Grisbrook et al., ${ }^{[36]}$ who showed that completing a 12-week exercise program would improve the QOL of these patients. The results of our study contradict with Roh et al., ${ }^{[37]}$ who showed that the impact of skin rehabilitation program on the QOL of burn patients is not significant and the study recommended that further studies with the use of the program should be done with more samples and in a longer duration.

\subsection{Considering relation between burn data and self- esteem and correlation between self-esteem and QOL of studied group}

The current study showed that there was a significant relation between self-esteem and site and extent of the burn. This result consisted with Faisal et al., ${ }^{[38]}$ who reported that there was a significant association between facial burns and lower self-esteem. Also Zorita et al. ${ }^{[30]}$ revealed that there was a significant relation between site of burn where occur and self-esteem and also the severity and extent of the burn had a negative effect on self-esteem especially the burn affect appearance areas. While the result of current study inconsistent with Hoogewerf et al., ${ }^{[39]}$ who founded that patientrated facial scar severity was not predictive for self-esteem and depressive symptoms six months post-burn. There was, however, a significant relationship between early depressive symptoms and both patient-rated facial scar severity and subsequent self-esteem. Our study revealed that there was positive correlation between self-esteem and QOL especially in Psychological and Social domain of QOL. This result in the same line with Zorita et al., ${ }^{[30]}$ who found positive correlation between self-esteem and QOL and the study also revealed the Low self-esteem was correlated with poor general and mental health and low vitality.

From the study, the researchers found a lot of physical, psychological, social, and economic complications that have been reported as a result of burn that have a negative impacts on self-esteem and QOL of these patients. Therefore reducing these effects of burned patients through promoting self-care nursing intervention model when providing nursing care helping patients for recovery and in coping process from all aspects; physically, psychologically and socially and prevent future episodes of self-aggression, that lead to improvement of self-esteem and QOL.

\section{Conclusions}

The overall findings in the present study revealed that applying self-care education based on Orem's theory when providing nursing intervention at burn unit was effective 
when providing care on the principles of proper nutrition and diet, proper use of medications, pain management (pharmacological and non-pharmacological), burned skin and the wound, dressing, methods to compensate for the inability to adjust temperature, exercise and physical therapy programs, uttering the changes in feelings about self-image, ways to promote coping with the changes, strengthening the ability and enhancing of self-esteem, using relaxation techniques, providing mental health and sexual relations (in married patients). Encouraged patient to be active participant in care and had brought about significant improvement of self-care management, self-esteem and QOL of burn patients.

\section{RECOMMENDATIONS FOR PRACTICE AND RE- SEARCH}

- The self-care theory has shown to be the basis when providing nursing care as it helps in promoting therapeutic communication and trust relationship between the patient and the nurse so that encourage nurses to work and providing care with nursing theories.

- Replication of the study using a larger probability sample from different geographical areas to help for generalization of the results.

\section{CONFlicts OF InTEREST Disclosure}

The authors declare they have no conflicts of interest.

\section{REFERENCES}

[1] Pope S, Solomons W, Done J, et al. Body image, mood and quality of life in young burn survivors. Burns. 2007; 33(6): 747-755. PMid: 17707785. https://doi.org/10.1016/j.burns. 2006 .10 .387

[2] Mock C, Peck M, Peden M, et al. WHO plan for burn prevention and care. Geneva: World Health Organization; 2008.

[3] Ghorbani F, Seifi B, Mohammadzade S, et al. Microbiological factors in burn wound infection in patients hospitalized in zanjan. Nursing Research. 2011; 6: 65-72.

[4] American Burn Association. Burn incidence and treatment in the United State. 2015. Available from: www . ameriburn.org/resour ces_factsheet.php

[5] Liliane M, AmaralZorita R, Leila Blanes N, et al. Health-related Quality of Life and Self-esteem Among Burn Patients. Wounds A Compendium of Clinical Research \& Practice. 2016; 28(1): 27-34.

[6] Cobb N, Maxwell G, Silverstein P. Patient perception of quality of life after burn injury: Results of an eleven year survey. J Burn Care Rehabil. 2012; 11: 330. https://doi.org/10.1097/00004630 $-199007000-00011$

[7] McKibben J, Ekselius L, Gisarek D, et al. Epidemiology of burn injuries II: Psychiatric and behavioral perspectives. International Review of Psychiatry. 2009; 21: 512-521. PMid: 19919204. https : //doi.org/10.3109/09540260903343794

[8] Van Loey N, Van Son M, Van der Heijden P, et al. PTSD in persons with burns: an explorative study examining relationships with attributed responsibility, negative and positive emotional states. Burns. 2013; 34: 1082-1089. PMid: 18511200. https://doi.org/10.1 016/j . burns . 2008. 01.012

[9] Sideli L, Prestifilippo A, Di Benedetto B, et al. Quality of life, body image, and psychiatric complications in patients with a burn trauma: preliminary study of the Italian version of the Burn Specific Health Scale-Brief. Ann Burns Fire Disasters. 2015; 23(4): 171-176.

[10] Al-Mousawi A, Mecott-Rivera G, Jeschke M, et al. Burn teams and burn centers: the importance of a comprehensive team approach to burn care. Clin Plast Surg. 2009; 36(4): 547-554. PMid: 19793550. https://doi.org/10.1016/j.cps.2009.05.015

[11] Partridge J. History of Burns. N Engl J Med. 2008; 352: 103. https://doi.org/10.1056/NEJM200501063520126
[12] Grisbrook TL, Reid SL, Edgar DW, et al. Exercise training to improve health related quality of life in long term survivors of major burn injury: A matched controlled study. Burns. 2012; 38: 116573. PMid: 22538174 . https ://doi.org/10.1016/j.burns . 20 12.03 .007

[13] Keshtkaran Z, Ghodsbin F, Solouki S, et al. The impact of self-care Education on quality of life of those clients suffering from osteoarthritis in rehabilitation centers of shiraz university of medical science. Journal of Babol University of Medical Sciences. 2010; 12: 65-70.

[14] Rostami M, Baraz-Pordanjani SH, Farzianpour F, et al. Effect of oremself care model on ederies quality of life in health care centers of masjedsolaiman in 2007-2008. Journal of Arak University of Medical Sciences. 2009; 12: 51-9.

[15] Cox A, Hayter M, Ruane J. Alternative approaches to enhanced observations in acute inpatient mental health care: a review of the literature. J Psychiatr Ment Health Nurs. 2010; 17: 162-71. PMid: 20465762. https://doi.org/10.1111/j.1365-2850.2009.01507.x

[16] Tomey AM, Alligood MR. Nursing theorists and their work. $5^{\text {th }}$ ed. Mosby, Philadelphia; 2002.

[17] George JB. Nursing Theories: The Base for Professional Nursing Practice. $5^{\text {th }}$ ed. New Jersey: Prentice Hall; 2002.

[18] Alligood MR, Tomey AM. Nursing Theory: Utilization \& Application. $3^{r d}$ ed. Missouri: Elsevier Mosby Publications; 2002.

[19] Orem DE. Nursing: concepts of practice. $6^{t h}$ ed. St. Louis: Mosby; 2001.c

[20] Marquis BL, Huston CJ. Leadership roles and management functions in nursing: theory and application. Philadelphia: Lippincott Williams \& Wilkins; 2009.

[21] Al-Khaled T, Zahran E, El Soussi A. Nurses' related factors influencing the use of physical restraint in critical care units. J Am Sci. 2011; 7: 13-22.

[22] Garas A, Ahmed B, Badr M. Compliance among hemodialysis patient' suggestive teaching program, Rosenberg's Global self-esteem scale. The New Egyptian Journal of Medicine. 1991; 5(11): 12-19.

[23] Hassan S. Relationship between Quality of life and psychological status among patients with stroke. Rosenberg's Global self-esteem scale 1991. Master Thesis. 2006.

[24] WHO-QOL Group. The Development of World Health Organization Quality of Life Assessment Instrument-The (WHOQOL). In Orley, 
J. \& Kuyken, W. (Eds.). Quality of life assessment international perspectives. Berlin: Springer; 1997. 41-57 p.

[25] Fok MS, Wong TK. Clinical application of Orem's self-care model of nursing in a Chinese community. Transcultural Nur. 2003; 15: 262-72. https://doi.org/10.5172/conu.15.3.262

[26] Faisal A, Hussain N, Jawed H. Self-esteem in Male and Female Patients of Facial Burn Injuries in Karachi. Pakistan Business Review. 2015; 17(3).

[27] Tirumala N, Kumar SV, Sathyadev M, et al. Assessment of quality of life in Thermal (flame) burn patients: An observational study at Tertiary Care Teaching Hospital in Warangal, A.P., India. Int. J. of Pharm. \& Life Sci. (IJPLS). 2013; 4(12).

[28] Ciofi-Silva CL, Rossi LA, Dantas RS, et al. The life impact of burns: the perspective from burn persons in Brazil during their rehabilitation phase. Disabil Rehabil. 2010; 32(6): 431-437. PMid: 20113190. https://doi.org/10.3109/09638280802532555

[29] Hashemi F, Dolatabad FR, Yektatalab Sh, et al. Effect of Orem Self-Care Program on the Life Quality of Burn Patients Referred to Ghotb-al-Din-e-Shirazi Burn Center, Shiraz, Iran: A Randomized Controlled Trial. Int J Community Based Nurs Midwifery. 2014; 2(1): 46-48.

[30] Zorita LA, Blanes L, Daniela F, et al. Health-related Quality of Life and Self-esteem Among Burn Patients. Wounds. 2016; 28(1): 27-34.

[31] Lo SF, Hayter M, Hsu M, et al. The effectiveness of multimedia learning education programs on knowledge, anxiety and pressure garment compliance in patients undergoing burns rehabilitation in Taiwan: an experimental study. Journal of Clinical Nursing. 2010 19: 129-37. PMid: 20500251. https ://doi.org/10.1111/j.13 $65-2702.2009 .03030 . \mathrm{x}$
[32] Radwan M, Samir S, Aty OA, et al. Effect of a rehabilitation program on the knowledge, physical and psychosocial functions of patients with burns. Journal of American Science. 2011; 7: 427-34.

[33] Poorgholami F, Javadpour S, Saadatmand V, et al. Effectiveness of Self-Care Education on the Enhancement of the Self-Esteem of Patients Undergoing Hemodialysis. Global Journal of Health Science. 2016; 8(2): 132-136.

[34] Pishnamazy Z, Kiani-Asiabar A, Heravi-Karimooi M, et al. Quality of life in burn patients. Journal of Payesh. 2012; 11: 103-10.

[35] Elsherbiny OEE, Salem MA, El-Sabbagh AH, et al. Quality of life of adult patients with severe burns. Burns. 2011; 37(5): 776-89. PMid: 21466924. https://doi.org/10.1016/j.burns. 2010 .12 .017

[36] Grisbrook TL, Reid SL, Edgar DW, et al. Exercise training to improve health related quality of life in long term survivors of major burn injury: A matched controlled study. Burns. 2012; 38: 116573. PMid: 22538174. https://doi.org/10.1016/j.burns. 20 12.03 .007

[37] Roh YS, Seo CH, Jang KU. Effects of a skin rehabilitation nursing program on skin status, depression, and burn-specific health in Burn survivors. Rehabil Nurs. 2010; 35: 65-9. PMid: 20306614. https://doi.org/10.1002/j.2048-7940.2010.tb00033.x

[38] Faisal A, Amjad A. Zehra N. Impact of facial burn injury on selfesteem of burn patients - a hospital based study from Karachi. J Dow Uni Health Sci. 2016; 10(1): 25-30.

[39] Hoogewerf CJ, VanBaar ME, middelkoop E, et al. Impact of facial burns: relationship between depressive symptoms, self-esteem and scar severity. General Hospital Psychiatry. 2014; 36(3): 271273. PMid: 24417954. https://doi.org/10.1016/j.genhos ppsych.2013.12.001 